\title{
Perbaikan Waktu Produksi Kran TX 116 Led (Series Ego) Dengan Metode Critical Path Method (CPM)
}

\author{
${ }^{1}$ Edi Supriyadi, ${ }^{2}$ Rully Nurdewanti, ${ }^{3}$ Nursadiah Rosidah \\ ${ }^{1,2}$ Program Studi Teknik Industri, Fakultas Teknik, Universitas Pamulang, \\ Tangerang Selatan \\ ${ }^{3}$ Mahasiswa Program Studi Teknik Industri, Fakultas Teknik, Universitas \\ Pamulang, Tangerang Selatan \\ J1. Surya Kencana No. 1, Pamulang, Indonesia 15417, Indonesia
}

Email: 1dosen00905@unpam.ac.id

\section{Tersedia Online di}

http://www.jurnal.unublitar.ac.id/ index.php/briliant

\begin{tabular}{l}
\hline Sejarah Artikel \\
\hline Diterima pada November 2020 \\
Disetuji pada Februari 2021 \\
Dipublikasikan pada Mei 2021 \\
Hal. 454-466 \\
\hline
\end{tabular}

\section{Kata Kunci:}

Proses produksi; Jaringan kerja; Metode Jalur Kritis

\section{DOI:}

http://dx.doi.org/10.28926/briliant .v3i4.588

\begin{abstract}
Abstrak: Proses produksi merupakan kegiatan mengubah bahan masukan menjadi bahan keluaran, baik bahan jadi maupun setengah jadi. Untuk menggambarkan proses tersebut perlu dilakukan urutan kegiatan yang dilokasikan dalam waktu yang tepat. Jalur kritis adalah jalur yang memiliki kegiatan dengan total waktu yang paling lama tetapi menunjukan waktu penyelesaian produksi yang tercepat. Critical Path Method (CPM) digunakan untuk menentukan jalur kritis sebuah proses produksi. Metode ini memecahkan masalah dengan perhitungan maju, perhitungan mundur, dan perhitungan kelonggaran waktu. Sehingga dapat memberikan masukan untuk perbaikan waktu yang telah ditetapkan sebelumnya. Dengan waktu proses produksi produk EGO TX 116 LED yaitu 4862 detik, maka diperoleh jalur kritis yang memiliki nilai TF $\mathrm{SF}=0$. Jalur kritis tersebut terdapat pada komponen II, dengan kegiatan $\mathrm{B}-\mathrm{F}-\mathbf{J}-\mathrm{M}-\mathrm{N}$ (machining\&welding polishing - plating - marking - assembling).
\end{abstract}

\section{PENDAHULUAN}

Manajemen sebagai ilmu mengelola suatu kegiatan yang skalanya dapat bersifat kecil atau bahkan sangat besar, mempunyai ukuran tersendiri pada hasil akhir. Mengerjakan proyek tepat waktu sesuai dengan biaya, lingkup pekerjaan, serta mutu yang sudah ditetapkan menjadi target setiap perusahaan. Beberapa kendala seperti tingkat SDM, sistem yang yang berjalan serta teknologi yang dipakai sangat menentukan kecepatan pengerjaan suatu proyek (Prastiwi, 2017). Belum lagi faktor cuaca, kondisi lapangan yang mungkin masih berupa hutan, atau sawah serta jalan menuju lokasi proyek sedikit banyak mempengaruhi tingkat kecepatan dalam pengerjaan proyek (Prasetya, 2018).

454 BRILIANT: Jurnal Riset dan Konseptual

Volume 6 Nomor 2, Mei 2021 
Dalam usaha memenangkan persaingan yang semakin ketat dalam industri manufaktur PT Surya Toto Indonesia, Tbk dituntut untuk selalu dapat mempertahankan dan meningkatkan daya saingnya. Faktor yang paling berpengaruh pada perusahaan adalah kelancaran dalam kegiatan produksi. Perusahaan harus mampu meningkatkan dan mempercepat proses produksi dengan mengkombinasikan faktor-faktor produksi secara efisien untuk mencapai pendapatan yang maksimal, tetapi perencanaan dan pengendalian proses produksi dalam sebuah perusahaan membutuhkan waktu yang harus diminimalisasi. Keberhasilan atau kegagalan dari pelaksanaan proyek sering terjadi karena kurang terencananya kegiatan proyek dan pengendalian yang kurang efektif, menjadikan kegiatan proyek tidak efisien. Hal ini menyebabkan keterlambatan waktu, menurunnya kualitas pekerjaan, dan membengkaknya biaya pelaksanaan (Nalhadi \& Suntana, 2017).

Untuk itu dalam perbaikan proses maka PT Surya Toto Indonesia, Tbk menggunakan metode Critical Path Method (CPM) karena dapat mengefisiensikan waktu proses dan sebagai rencana tindakan perbaikan masalah produksi pada TX 116 LED (Ego Series) yang selama ini banyak terjadi penyimpangan sehingga dapat mengurangi atau bahkan menghilangkan masalah tersebut.

Penjadwalan proyek membantu menunjukkan hubungan setiap aktivitas dengan aktivitas lainnya dan terhadap keseluruhan proyek, mengidentifikasi hubungan yang harus didahulukan diantara aktivitas, serta menunjukkan perkiraan waktu yang realistis untuk setiap aktivitas. CPM (Critical Path Methode) membuat asumsi bahwa waktu aktivitas yang diketahui dengan pasti sehingga hanya diperlukan satu faktor waktu untuk setiap aktivitas (Jannah et al., 2018). Salah satu keuntungan CPM berdasarkan (Iwawo et al., 2016) yaitu CPM cocok untuk formulasi, penjadwalan, dan mengelola berbagai kegiatan disemua pekerjaan konstruksi, karena menyediakan jadwal yang dibangun secara empiris.

Secara umum produksi diartikan sebagai suatu kegiatan atau proses yang menstransformasikan masukkan (input) menjadi hasil keluaran (output). Dalam pengertian yang bersifat umum ini penggunaannya cukup luas, sehingga mencakup keluaran (output) yang berupa barang atau jasa. Dalam arti sempit, pengertian produksi hanya dimaksud sebagai kegiatan yang menghsilkan barang baik barang jadi maupun barang setengah jadi, bahan industri dan suku cadang atau spareparts dan komponen. Hasil produksinya dapat berupa barang-barang konsumsi maupun barang-barang industri. Produksi adalah kegiatan untuk menciptakan atau menambah kegunaan suatu barang atau jasa.

Menurut Gray (2000) dalam (Aulady \& Orleans, 2016) jaringan kerja adalah framework untuk system informasi proyek yang akan digunakan oleh manajer proyek untuk membuat keputusan yang berhubungan dengan waktu, biaya, dan performance. Jaringan kerja memberikan waktu dimana kegiatan dapat dimulai dan diselesaikan dan kapan kegiatan dapat ditunda. 
Menurut Soeharto (1999) dalam (Perdana \& Rahman, 2019) CPM (Critical Path Method) memakai teknik penyajian secara gratis dengan memakai diagram anak panah, lingkaran serta kaidah-kaidah dasar logika ketergantungan dalam menyusun urutan kegiatan. Menurut Mulyono (2004) dalam (Perdana \& Rahman, 2019) model jaringan CPM tersusun atas dua komponen utama, yaitu titik-titik (nokhta/lingkaran) dan garis-garis (cabang/anak panah). Garis menunjukkan jenis kegiatan dari suatu proyek, sementara titik menunjukkan awal atau akhir suatu kegiatan atau biasa dinamakan events. Model jaringan juga menunjukkan berhubungan antara kegiatan-kegiatan. Ada suatu aturan dalam membuat model jaringan CPM, yaitu bahwa dua atau lebih kegiatan tak dapat secara serentak berawal dan berakhir pada lingkaran yang sama. Maka permasalahan tersebut dapat diatasi dengan suatu dummy activity. Suatu dummy activity digambarkan dengan anak panah terputus dan disisipkan pada jaringan itu untuk menunjukkan suatu precedence relationship. Suatu dummy activity tidak memakan waktu dan sumber daya, jadi waktu kegiatan dan biaya sama dengan nol. Kegiatan dummy dapat juga digunakan untuk menyusun suatu jaringan yang agar hubungan logikanya menjadi benar.

Sasaran utama analisis CPM adalah menentukan waktu terpendek yang diperlukan untuk menyelesaikan suatu proyek atau menentukan waktu yang diperlukan untuk suatu critical path, yaitu jalur waktu terlama. Kegiatan- kegiatan yang dilewati critical path dinamakan kegiatan kritis. Keterlambatan penyelesaian salah satu kegiatan ini akan menyebabkan keterlambatan penyelesaian proyek, karena itu kegiatan-kegiatan kritis perlu diawasi secara serius. Jika pengambil keputusan bermaksud mempercepat penyelesaian proyek, maka ia perlu memperpendek satu atau beberapa waktu kegiatan kritis.

Menurut Soeharto (1999) dalam (Perdana \& Rahman, 2019), Critical Path Method (CPM) menggunakan satu angka estimasi dan dalam praktek lebih banyak dipergunakan oleh kalangan industri atau proyek-proyek engineering konstruksi. Menurut Levin (1999) dalam (Jannah et al., 2018), Jika waktu dapat diperkirakan dengan cukup tepat dan biaya-biaya dapat dihitung sejak semula, maka lebih menguntungkan jika dipergunakan CPM. Kegiatan-kegiatan yang merupakan komponen proyek dan hubungan ketergantungan antara satu dengan yang lain disajikan dengan menggunakan tanda-tanda.

Critical Path Methode (CPM) (Prasetya, 2018) adalah suatu metode perencanaan dan pengendalian proyek-proyek yang merupakan sistem yang paling banyak digunakan diantara semua sistem yang memakai prinsip pembentukan jaringan. Dengan metode ini jumlah waktu yang dibutuhkan untuk menyelesaikan suatu proyek dianggap diketahui dengan pasti, demikian pula hubungan antara sumber yang digunakan dan waktu yang diperlukan untuk menyelesaikan proyek. Jadi CPM merupakan analisa jaringan kerja yang berusaha mengoptimalkan biaya total proyek yang bersangkutan.

456 BRILIANT: Jurnal Riset dan Konseptual Volume 6 Nomor 2, Mei 2021 


\section{METODE}

Penelitian ini menggunakan data primer yang diperoleh langsung dari sumbernya, diamati dan dicatat untuk pertama kalinya. Dalam mengumpulkan dan mendapatkan data primer adalah Observasi melalui pengamatan langsung untuk mendapatkan data yang aktual yang terjadi di lapangan, meliputi tahapan kegiatan proses produksi produk TX 116 LED. Interview dengan bagian-bagian yang terkait dengan masalah yang sedang diteliti yaitu di bagian proses produksi, meliputi data tahapan proses produksi serta ketetapan waktu produksi pada setiap aktifitas. Dokumentasi berupa, catatan atau arsip perusahaan yang diambil sesuai kebutuhan penelitian. Data sekunder diperoleh dari hasil penelitian kepustakaan dengan membaca dan mempelajari buku-buku dan literatur-literatur agar mendapatkan pengertian tentang teori-teori serta metode analisis yang berhubungan dengan objek yang diteliti.

Teknik pengumpulan data melalui pengamatan langsung untuk mendapatkan data yang aktual yang terjadi di lapangan, untuk membetuk jaringan kerja. Setelah diperoleh jaringan kerja maka langkah selajutnya adalah menentukan jalur kritisnya. Terdiri dari dua tahap, yaitu perhitungan maju (forward computation) dan perhitungan mundur (backward computation)(Aulady \& Orleans, 2016).

Tahapan metode analisis data pada penelitian ini adalah sebagai berikut:

a. Mengumpulkan data proses produksi kran TX 116 LED

b. Menghitung waktu proses produksi karan TX 116 LED

c. Pembuatan jaringan kerja

d. Perhitungan waktu penyelesaian

e. Menentukan jalur kritis

f. Perbandingan waktu produksi

\section{HASIL DAN PEMBAHASAN}

Penghitungan waktu pengerjaan proses produksi dilakukan dengan menggunakan penghitungan waktu melalui pengamatan langsung dilapangan terhadap proses kerja dari tiap proses-proses produksi (Hardiyanto, 2018). Berikut masing-masing kegiatan dalam proses produksi EGO TX 116 LED dapat dilihat pada Tabel 1.

Tabel 1. Kegiatan Proses Produksi Produk TX 116 LED

\begin{tabular}{cclcc}
\hline Network & Aktifitas & \multicolumn{1}{c}{ Jenis Kegiatan } & Waktu (Detik) & Pendahulu \\
\hline $0-1$ & A & Forging komponen III & 19 & - \\
$0-2$ & B & Machining \& Welding komponen II & 942 & - \\
$0-3$ & C & Machining komponen I & 248 & - \\
$0-4$ & D & Injection komponen III & 24 & - \\
5-Jan & E & Machining komponen III & 239 & A \\
6-Feb & F & Polishing komponen II & 652 & B
\end{tabular}

BRILIANT: Jurnal Riset dan Konseptual

Volume 6 Nomor 2, Mei 2021 


\begin{tabular}{cclcc}
\hline Network & Aktifitas & \multicolumn{1}{c}{ Jenis Kegiatan } & Waktu (Detik) & Pendahulu \\
\hline 7-Mar & G & Polishing komponen I & 445 & $\mathrm{C}$ \\
10-Apr & H & Plating plastik komponen III & 2280 & D \\
8-May & I & Polishing komponen III & 132 & E \\
9-Jun & J & Plating komponen II & 2290 & $\mathrm{~F}$ \\
10-Jul & K & Plating komponen I & 2280 & $\mathrm{G}$ \\
10-Aug & L & Plating komponen III & 2280 & $\mathrm{I}$ \\
10-Sep & M & Marking komponen II & 30 & $\mathrm{~J}$ \\
11-Oct & $\mathrm{N}$ & Assembling komponen I, II, \& III & 948 & $\mathrm{H}, \mathrm{K}, \mathrm{M}, \mathrm{L}$ \\
\hline \multicolumn{5}{l}{ Sesuai dengan tabel diatas maka bentuk jaringan kerjanya adalah sebagai }
\end{tabular}
berikut.

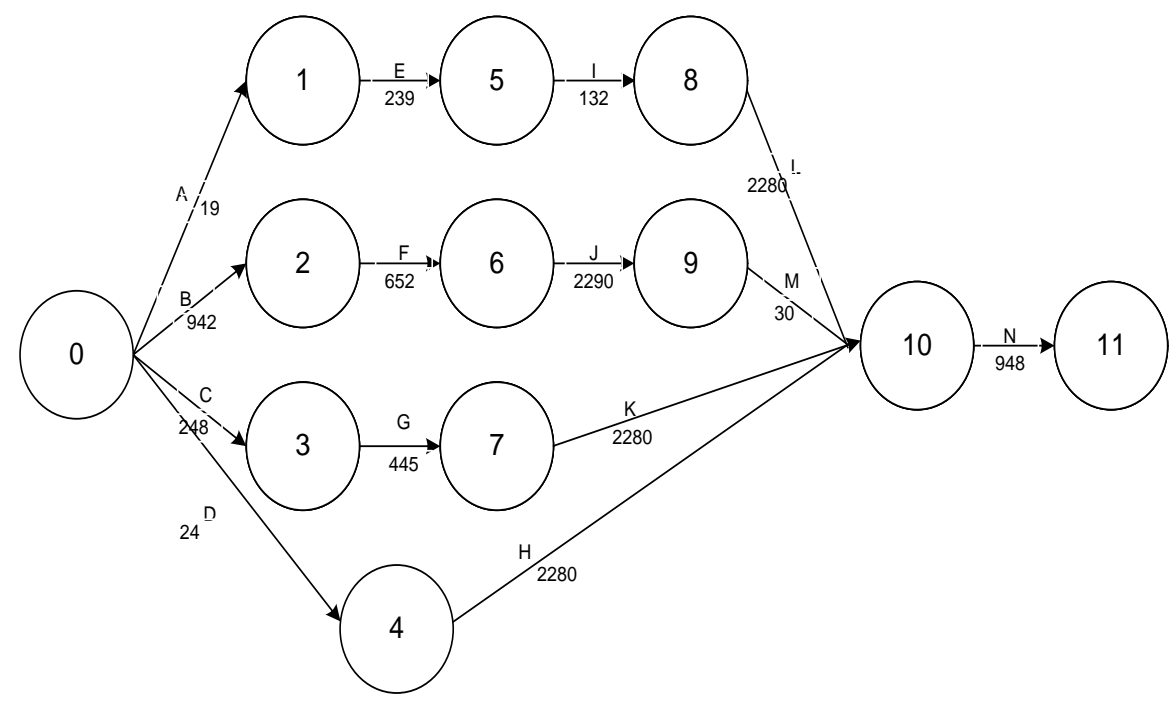

Gambar 1. Peta Jaringan Kerja Proses Produksi Produk TX116LED (PT. Surta Toto Indonesia, Tbk, 2020)

\section{Perhitungan Maju (Forward Computation)}

Waktu pelaksanaan (duration) pada kegiatan A adalah 19 detik, sehingga saat tercepat diselesaikannya aktivitas A atau $\operatorname{EF}(0,1)=19$, Untuk kegiatan lainnya dapat dilihat dalam Tabel 2 di bawah ini. 
Tabel 2. Hasil Analisa Perhitungan Maju

\begin{tabular}{|c|c|c|c|c|}
\hline Event & $\begin{array}{c}\text { Kegiatan } \\
\quad(i-j)\end{array}$ & $\begin{array}{l}\text { Waktu } \\
\text { (detik) }\end{array}$ & $\begin{array}{c}\text { Paling } \\
\text { Mulai } \\
\text { (ES) }\end{array}$ & $\begin{array}{l}\text { Awal } \\
\text { Selesai } \\
\text { (EF) }\end{array}$ \\
\hline 0 & - & 0 & 0 & 0 \\
\hline 1 & $0-1$ & 19 & 0 & 19 \\
\hline 2 & $0-2$ & 942 & 0 & 942 \\
\hline 3 & $0-3$ & 248 & 0 & 248 \\
\hline 4 & $0-4$ & 24 & 0 & 24 \\
\hline 5 & $1-5$ & 239 & 19 & 258 \\
\hline 6 & $2-6$ & 652 & 942 & 1594 \\
\hline 7 & $3-7$ & 445 & 248 & 693 \\
\hline 8 & $4-10$ & 132 & 258 & 390 \\
\hline \multirow[t]{2}{*}{9} & $5-8$ & 2290 & 1594 & 3884 \\
\hline & $8-10$ & 2280 & 390 & 2670 \\
\hline Merge & $9-10$ & 30 & 3884 & 3914 \\
\hline \multirow[t]{2}{*}{ Event } & $7-10$ & 2280 & 693 & 2973 \\
\hline & 4-10 & 2280 & 24 & 2304 \\
\hline 10 & \multicolumn{3}{|c|}{$\begin{array}{c}\text { Nilai Maksimal Merge } \\
\text { Event }\end{array}$} & 3914 \\
\hline 11 & $10-11$ & 948 & 3914 & 4862 \\
\hline
\end{tabular}

\section{Perhitungan Mundur (Backward Computation)}

LF 11 merupakan aktifitas akhir, sehingga LF adalah $=4862$ detik, LF $10=$ LS (10-11) - Durasi $=4862-948=3948$, selanjutnya dapat dilihat dalam Tabel 3. di bawah ini:

Tabel 3. Hasil Analisa Perhitungan Mundur

\begin{tabular}{|c|c|c|c|c|}
\hline \multirow[t]{2}{*}{$\overline{\text { Event }}$} & \multirow{2}{*}{$\begin{array}{c}\text { Kegiatan } \\
(\mathrm{i}-\mathrm{j})\end{array}$} & \multirow{2}{*}{$\begin{array}{l}\text { Waktu } \\
\text { (Detik) }\end{array}$} & \multicolumn{2}{|c|}{ Paling Akhir } \\
\hline & & & LS & LF \\
\hline 11 & 11 & 0 & 0 & 4862 \\
\hline 10 & $10-11$ & 948 & 4862 & 3914 \\
\hline 9 & $9-10$ & 30 & 3914 & 3884 \\
\hline 8 & $8-10$ & 2280 & 3914 & 1634 \\
\hline 7 & $7-10$ & 2280 & 3914 & 1634 \\
\hline 6 & $6-9$ & 2290 & 3884 & 1594 \\
\hline 5 & $5-8$ & 132 & 1634 & 1502 \\
\hline 4 & $4-10$ & 2280 & 3914 & 1634 \\
\hline 3 & $3-7$ & 445 & 1634 & 1189 \\
\hline 2 & $2-6$ & 652 & 1594 & 942 \\
\hline \multirow[t]{2}{*}{1} & $1-5$ & 239 & 1502 & 1263 \\
\hline & $0-1$ & 19 & 1263 & 1244 \\
\hline Burst & $0-2$ & 942 & 942 & 0 \\
\hline \multirow[t]{2}{*}{ Event } & $0-3$ & 248 & 1189 & 941 \\
\hline & $0-4$ & 24 & 1634 & 1610 \\
\hline 0 & Nilai M & nal $B$ & t Even & 0 \\
\hline
\end{tabular}




\section{Perhitungan Kelonggaran Waktu (Slack/Float)}

$\mathrm{A}(0,1) \mathrm{TF}=1263-19-0=1244$

$\mathrm{FF}=19-19-0=0$

$\mathrm{B}(0,2) \mathrm{TF}=942-942-0=0$

$\mathrm{FF}=942-942-0=0$

Begitu juga selanjutnya, hasil perhitungan total float dan free float dapat dilihat dalam Tabel 4 di bawah ini.

Tabel 4. Total Float- Free Float Hasil Analisa

\begin{tabular}{|c|c|c|c|c|c|c|c|c|}
\hline \multirow[b]{2}{*}{ Kegiatan } & \multirow[b]{2}{*}{ Pendahulu } & \multirow[b]{2}{*}{$\begin{array}{c}\text { Durasi } \\
\text { (Detik) }\end{array}$} & \multicolumn{2}{|c|}{ Paling Cepat } & \multicolumn{2}{|c|}{ Paling Lambat } & \multirow{2}{*}{$\begin{array}{l}\text { Total } \\
\text { Float } \\
\text { (TF) }\end{array}$} & \multirow{2}{*}{$\begin{array}{l}\text { Free } \\
\text { Float } \\
(\mathrm{FF})\end{array}$} \\
\hline & & & $\begin{array}{c}\text { Mulai } \\
\text { ES }\end{array}$ & $\begin{array}{c}\text { Selesai } \\
\text { EF }\end{array}$ & $\begin{array}{c}\text { Mulai } \\
\text { LS }\end{array}$ & $\begin{array}{c}\text { Selesai } \\
\text { LF }\end{array}$ & & \\
\hline A & - & 19 & 0 & 19 & 0 & 1263 & 1244 & 0 \\
\hline B & - & 942 & 0 & 942 & 0 & 942 & 0 & 0 \\
\hline $\mathrm{C}$ & - & 248 & 0 & 248 & 0 & 1189 & 941 & 0 \\
\hline $\mathrm{D}$ & - & 24 & 0 & 24 & 0 & 1634 & 1610 & 0 \\
\hline $\mathrm{E}$ & A & 239 & 19 & 258 & 1263 & 1502 & 0 & 0 \\
\hline $\mathrm{F}$ & B & 652 & 942 & 1594 & 942 & 1594 & 0 & 0 \\
\hline G & $\mathrm{L}$ & 445 & 248 & 693 & 1189 & 1634 & 0 & 0 \\
\hline $\mathrm{H}$ & $\mathrm{D}$ & 2280 & 24 & 3914 & 1634 & 3914 & 0 & 1610 \\
\hline I & $\mathrm{E}$ & 132 & 258 & 390 & 1502 & 1634 & 0 & 0 \\
\hline $\mathrm{J}$ & $\mathrm{F}$ & 2290 & 1594 & 3884 & 1594 & 3884 & 0 & 0 \\
\hline K & $\mathrm{G}$ & 2280 & 693 & 3914 & 1634 & 3914 & 0 & 941 \\
\hline $\mathrm{L}$ & I & 2280 & 390 & 3914 & 1634 & 3914 & 0 & 1244 \\
\hline M & $\mathrm{J}$ & 30 & 3884 & 3914 & 3884 & 3914 & 0 & 0 \\
\hline $\mathrm{N}$ & $\mathrm{L}, \mathrm{M}, \mathrm{K}, \mathrm{H}$ & 948 & 4862 & 3914 & 4862 & 3914 & 0 & 0 \\
\hline
\end{tabular}

Dari hasil perhitungan diatas, maka jalur kritis proses produksi EGO TX 116 LED dapat dilihat dalam Gambar 2 berikut. 


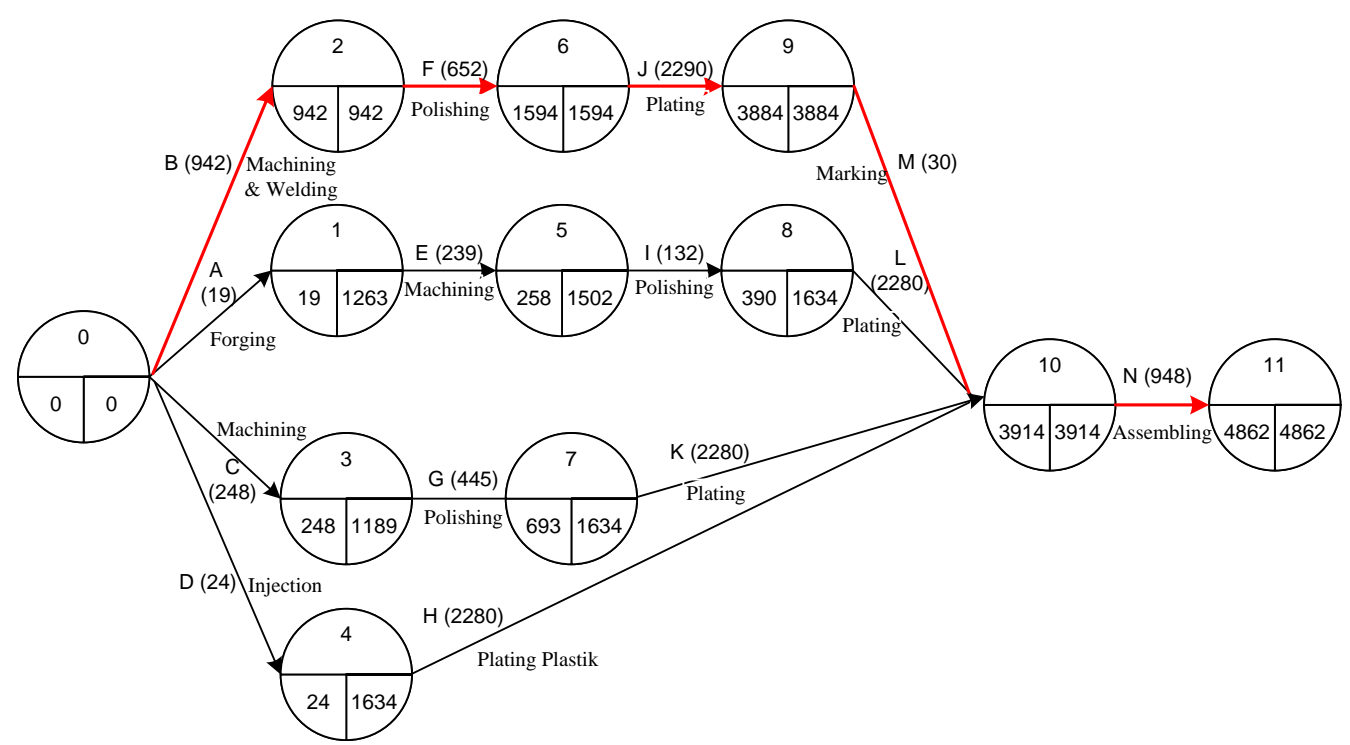

Gambar 2. Jalur Kritis Proses Produksi Produk TX116LED (Pengolahan Penelitian, 2020)

Maka telah diketahui bahwa waktu total proses produksi EGO TX 116 LED adalah 4862 detik. Jalur kritis digambarkan dalam tanda panah merah, terdapat pada komponen II yaitu pada kegiatan machining\&welding, polishing, plating, marking, dan assembling.

\section{Perbaikan Waktu Proses Produksi}

Setelah diperoleh jalur kritis pada kompone II, sesuai dengan hasil pengolahan data dilapangan maka yang paling memungkinkan untuk pengusulan perbaikan yaitu pada proses kegiatan machining \& welding. Dimana kegiatan tersebut dijabarkan dalam Tabel 5 di bawah ini.

Tabel 5. Rincian Kegiatan Machining \&Welding

\begin{tabular}{clc}
\hline Aktifitas & \multicolumn{1}{c}{ Kegiatan } & $\begin{array}{c}\text { Waktu } \\
\text { (Detik) }\end{array}$ \\
\hline $\mathrm{A}$ & Cutting & 24 \\
$\mathrm{~B}$ & Anealing & 20 \\
$\mathrm{C}$ & Bending & 28 \\
$\mathrm{D}$ & NC Forging & 65 \\
$\mathrm{E}$ & MC Centre & 36 \\
$\mathrm{~F}$ & Cutting\&NC Forging & 51 \\
$\mathrm{G}$ & MC Centre & 124 \\
$\mathrm{H}$ & Welding & 170 \\
$\mathrm{I}$ & Cuci Asam & 48 \\
$\mathrm{~J}$ & NC Forging & 174 \\
$\mathrm{~K}$ & NC Centre & 72 \\
$\mathrm{~L}$ & Drill 1 & 40
\end{tabular}




\begin{tabular}{ccc} 
M & Drill 2 & 40 \\
$\mathrm{~N}$ & Anealing & 50 \\
& Waktu Total & $\mathbf{9 4 2}$ \\
\hline
\end{tabular}

Pada kegiatan L dan M, kegiatan tersebut menggunakan mesin yang sama. Dimana kegiatan tersebut adalah pemberian lubang pada komponen untuk pemasangan (baut) dengan ukuran 2x diameter $8 \mathrm{~mm}$ dengan waktu masing-masing kegiatan 40 detik, sehingga kedua proses tersebut memakan waktu 80 detik. Apabila dengan mesin drill 1 sekaligus dapat diberi lubang 4x diameter $8 \mathrm{~mm}$ maka proses drill 2 dapat dihilangkan. Tentu saja hali ini dapat diwujudkan dengan memakai mesin drill yang baru dengan 4 material untuk dapat membuat lubang pada part yang diproduksi. Usulan perbaikan dapat dilihat dalam Gambar 3 di bawah ini.

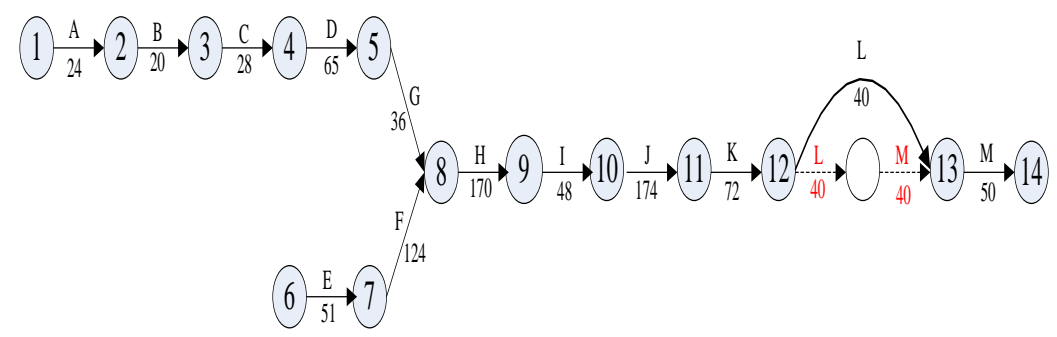

Gambar 3. Usulan perbaikan Proses Produksi Produk TX116LED (Pengolahan Penelitian, 2020)

Waktu proses sebelumnya adalah 942 detik, dengan menggabungkan aktifitas L dan M, sehingga waktu yang diperoleh dari proses machining \& welding menjadi 902 detik.

\section{Perbandingan Hasil Analisa Dengan Perbaikan Waktu Proses}

Setelah diusulkan dalam pembahasan di atas, maka perbaikan waktu dalam proses produksi EGO TX 116 LED dapat dilihat perbedaannya Gambar 4 dibawah ini: 


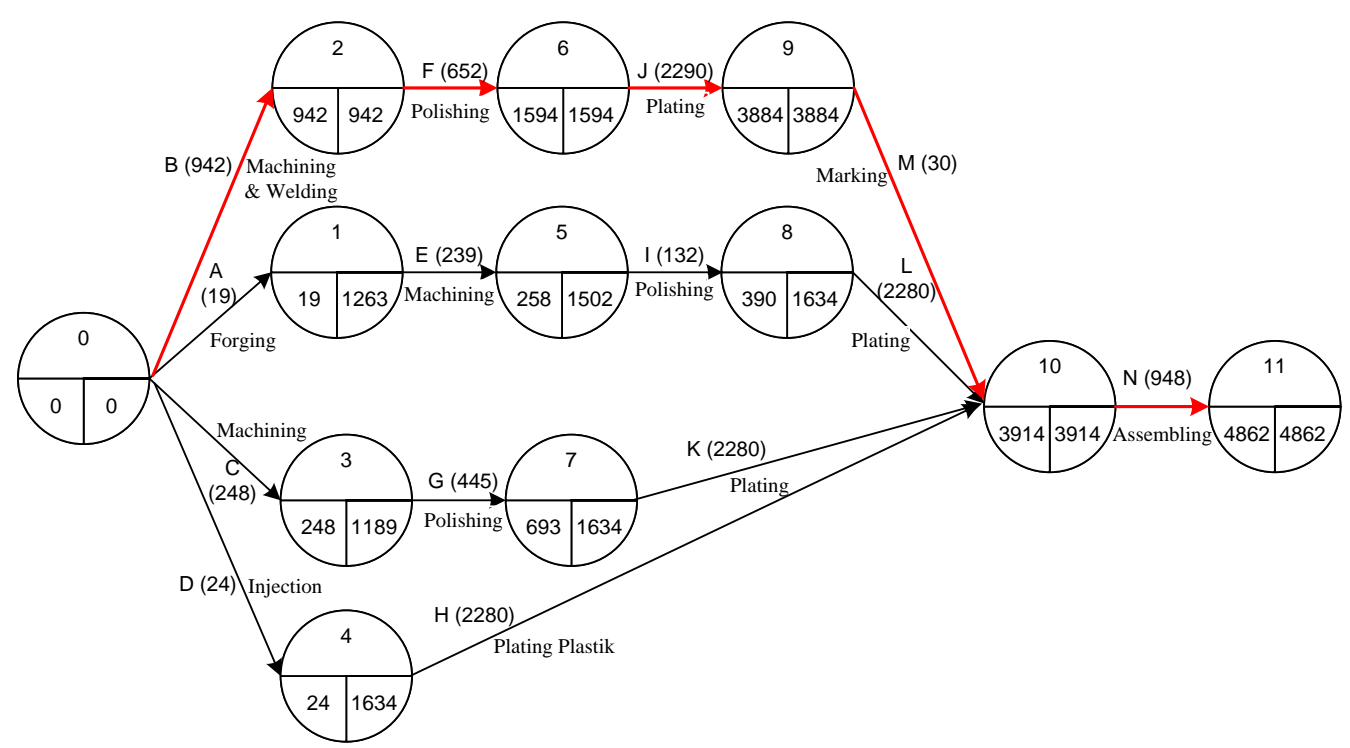

Gambar 4. Perbaikan Waktu Proses Produksi Produk TX116LED (Pengolahan Penelitian, 2020)

Gambar diatas merupakan hasil dari analisa dengan metode jalur kritis. Sesuai dengan pambahasan pada hasil analisa, telah diketahui jalur kritis pada proses produksi TX 116 LED terletak pada aktifitas B $-\mathrm{F}-\mathrm{J}-\mathrm{M}-\mathrm{N}$ dengan waktu total produksi 4862 detik.

\section{Usulan Perbaikan Waktu Proses Dengan Critical Path Method}

Dengan perhitungan yang sama, yaitu Perhitungan Maju (Forward Computation), Perhitungan Mundur (Backward Computation), dan Kelonggaran Waktu (Slack/Float) maka hasil perhitungannya dapat dilihat dalam Tabel 6 di bawah ini:

Tabel 6. Usulan Perbaikan Waktu Total Float-Free Float

\begin{tabular}{|c|c|c|c|c|c|c|c|c|}
\hline \multirow[b]{2}{*}{ Kegiatan } & \multirow[b]{2}{*}{ Pendahulu } & \multirow[b]{2}{*}{$\begin{array}{l}\text { Durasi } \\
\text { (Detik) }\end{array}$} & \multicolumn{2}{|c|}{ Paling Cepat } & \multicolumn{2}{|c|}{ Paling Lambat } & \multirow{2}{*}{$\begin{array}{l}\text { Total } \\
\text { Float } \\
\text { (TF) }\end{array}$} & \multirow{2}{*}{$\begin{array}{c}\text { Free } \\
\text { Float } \\
\text { (FF) }\end{array}$} \\
\hline & & & $\begin{array}{c}\text { Mulai } \\
\text { ES }\end{array}$ & $\begin{array}{c}\text { Selesai } \\
\text { EF }\end{array}$ & $\begin{array}{c}\text { Mulai } \\
\text { LS }\end{array}$ & $\begin{array}{c}\text { Selesai } \\
\text { LF }\end{array}$ & & \\
\hline $\mathrm{A}$ & - & 19 & 0 & 19 & 0 & 1223 & 1204 & 0 \\
\hline B & - & 902 & 0 & 902 & 0 & 902 & 0 & 0 \\
\hline $\mathrm{C}$ & - & 248 & 0 & 248 & 0 & 1149 & 901 & 0 \\
\hline $\mathrm{D}$ & - & 24 & 0 & 24 & 0 & 1594 & 1570 & 0 \\
\hline $\mathrm{E}$ & A & 239 & 19 & 258 & 1223 & 1462 & 0 & 0 \\
\hline $\mathrm{F}$ & B & 652 & 902 & 1554 & 902 & 1554 & 0 & 0 \\
\hline G & $\mathrm{L}$ & 445 & 248 & 693 & 1149 & 1594 & 0 & 0 \\
\hline $\mathrm{H}$ & $\mathrm{D}$ & 2280 & 24 & 3874 & 1594 & 3874 & 0 & 1570 \\
\hline & & & & $\begin{array}{r}\mathrm{NT}: \\
\mathrm{Vc}\end{array}$ & 61 & or $2, \mathrm{M}$ & & \\
\hline
\end{tabular}




\begin{tabular}{ccccccccc} 
I & E & 132 & 258 & 390 & 1462 & 1594 & 0 & 0 \\
J & F & 2290 & 1554 & 3844 & 1554 & 3844 & 0 & 0 \\
K & G & 2280 & 693 & 3874 & 1594 & 3874 & 0 & 901 \\
L & I & 2280 & 390 & 3874 & 1594 & 3874 & 0 & 1204 \\
M & J & 30 & 3844 & 3874 & 3844 & 3874 & 0 & 0 \\
N & L,M,K,H & 948 & 4822 & 3874 & 4822 & 3874 & 0 & 0 \\
\hline
\end{tabular}

Aktifitas kritis mempunyai $\mathrm{TF}=\mathrm{FF}=0$. Sama halnya dengan hasil analisa, aktifitas kritisnya terletak pada aktifitas B, E, F, G, I, J, M dan N. Seperti yang dapat dilihat pada network modelling di bawah ini:

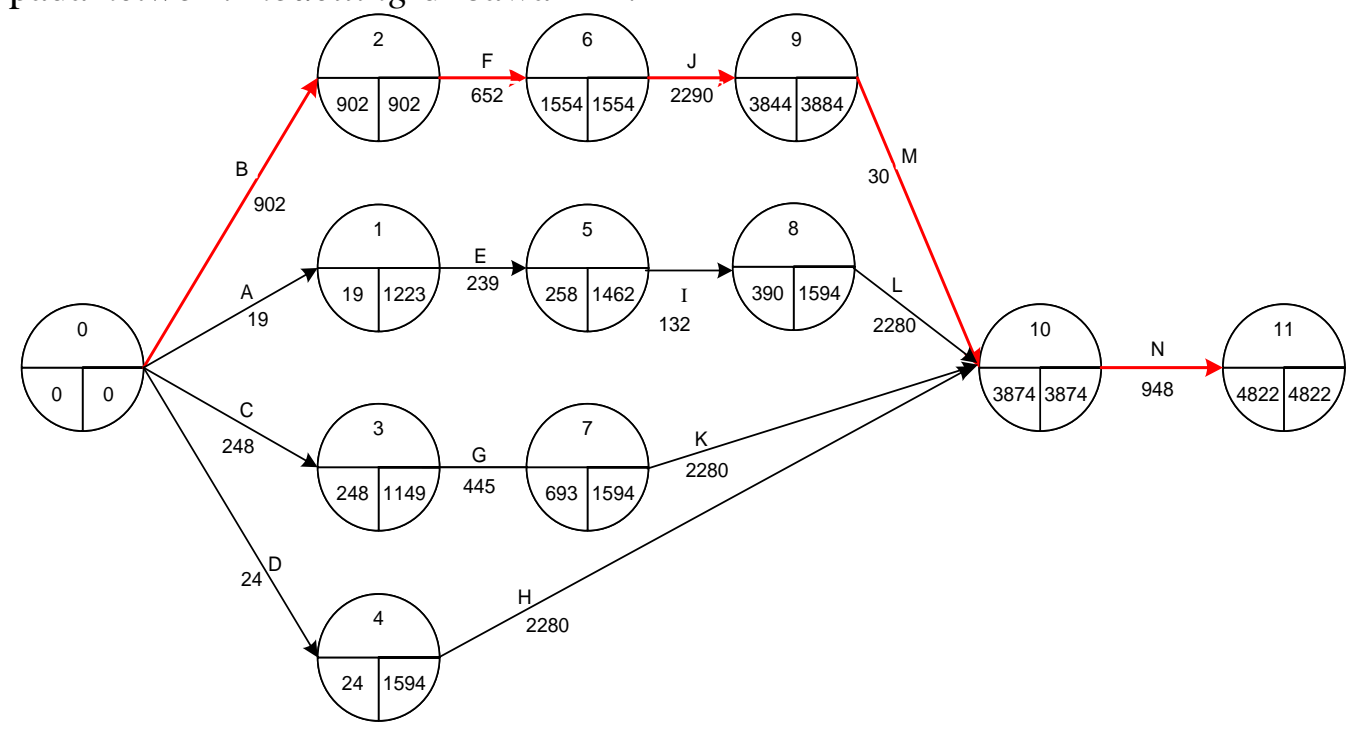

Gambar 5. Network Modelling Proses Produksi Produk TX116LED (Pengolahan Penelitian, 2020)

Tanda panah merah merupakan jalur kritis yang terdapat pada kompnen II dengan kegiatan $\mathrm{B}-\mathrm{F}-\mathrm{J}-\mathrm{M}-\mathrm{N}$. Sehingga diperoleh total waktu proses produksi produk EGO TX 116 LED adalah 4822 detik.

Hasil perbandingan antara hasil analisa dengan usulan perbaikan waktu proses produksi dengan critical path method adalah memiliki selisih waktu 40 detik dari total waktu produksi awal yaitu 4862 detik menjadi 4822 detik. Usulan ini dapat direalisasikan dengan penggunaan mesin drill yang memiliki 4 mata ulir. Selisih waktu ini tentunya sangat berpengaruh terhadap perusahaan, dimana selisih waktu ini terdapat dalam satu periode produksi. Semakin banyak produk yang di produksi, maka semakin banyak pula waktu proses produksi yang dubutuhkan. Semakim minimalnya waktu proses produksi, maka semakin besar jumlah produk yang dapat diproduksi. Sehingga perusahaan akan mendapatkan keuntungan yang lebih besar dan juga efisien dalam waktu proses produksi.

464 BRILIANT: Jurnal Riset dan Konseptual Volume 6 Nomor 2, Mei 2021 


\section{KESIMPULAN}

Waktu proses produksi produk EGO TX 116 LED yaitu 4862 detik, waktu tersebut diperoleh dari hasil analisa dengan Critical Path Method. Aplikasi dari Critical Path Method pada produk EGO TX 116 LED telah memperoleh kegiatan yang termasuk kedalam jalur kritis. Kegiatan tersebut terdapat pada komponen II, dengan kegiatan $\mathrm{B}-\mathrm{F}-\mathrm{J}-\mathrm{M}-\mathrm{N}$ (machining\&welding - polishing - plating marking - assembling)

\section{SARAN}

Perbaikan yang diusulkan dalam proses produksi TX 116 LED yaitu pada proses machining \& welding (B) pada komponen II. Penggabungan aktifitas pada mesin drill 1 dan drill 2 yang memiliki waktu proses 80 detik, menjadi satu mesin drill saja sehingga proses tersebut membutuhkan waktu 40 detik. Bila dilihat dari segi efisiensi waktu proses produksi, perusahaan diharapkan mampu merealisasikannya, karena telah dibandingkan dari waktu proses sebelumnya diketahui 942 detik, menjadi 902 detik.

Perbandingan waktu proses produksi EGO TX 116 LED dari hasil analisa data adalah 4862 detik, sedangkan hasil dari usulan perbaikan proses produksi adalah 4822 detik. Maka selisih waktu proses produksi adalah 40 detik.

\section{DAFTAR RUJUKAN}

Aulady, M. F. N., \& Orleans, C. (2016). Perbandingan Durasi Waktu Proyek Konstruksi Antara Metode Critical Path Method (CPM) dengan Metode Critical Chain Project Management (Studi Kasus: Proyek Pembangunan Apartamen Menara Rungkut). Jurnal IPTEK, 20(1), 13. https://doi.org/10.31284/j.iptek.2016.v20i1.29

Hardiyanto, S. (2018). Optimalisasi Proyek Pembangunan Gedung Parkir Dan Masjid RSUD Pare Oleh PT Arwi Graha Sejahtera Dengan Metode Jalur Kritis (Critical Path Method). Universitas Nusantara PGRI Kediri, 01, 113.http://simki.unpkediri.ac.id/mahasiswa/file_artikel/2018/14.1.02.02.022 3.pdf

Iwawo, E. R. M., Tjakra, J., \& Pratasis, P. A. K. (2016). Penerapan Metode Cpm Pada Proyek Konstruksi (Studi Kasus Pembangunan Gedung Baru Kompleks Eben Haezar Manado). Jurnal Sipil Statik, 4(9), 551-558.

Jannah, S. R., Muzdalifah, L., \& Kurniawati, E. F. (2018). Optimasi waktu penjadwalan proyek pembangunan perumahan menggunakan Critical Path Method (CPM) /Program Evaluation and Review Tehnique (PERT) dan Simulasi Monte Carlo (Studi Kasus CV. Granada Property). Prosiding SNasPPM， 3(1), 461-465. http://prosiding.unirow.ac.id/index.php/ SNasPPM/article/view/159/228

Nalhadi, A., \& Suntana, N. (2017). Analisa Infrastruktur Desa Sukaci-Baros 
Dengan Metode Critical Path Method (CPM). Jurnal Sistem Dan Manajemen Industri, 1(1), 35. https://doi.org/10.30656/jsmi.v1i1.167

Perdana, S., \& Rahman, A. (2019). PENERAPAN MANAJEMEN PROYEK DENGAN METODE CPM (Critical Path Method) PADA PROYEK PEMBANGUNAN SPBE. Amaliah: Jurnal Pengabdian Kepada Masyarakat, 3(1), 242-250. https://doi.org/10.32696/ajpkm.v3i1.235

Prasetya, E. B. (2018). Aplikasi Manajemen Proyek Konstruksi dengan Metode Critical Path dan Earned Value Management. RESISTOR (ElektRonika KEndali TelekomunikaSI Tenaga LiSTrik KOmputeR), 1(2), 53.

Prastiwi, L. (2017). Penerapan Metode Jalur Kritis Atau Critical Path Method (Cpm) Penentuan Waktu Optimal Dalam Proses Pembuatan Kerajinan Tenun Ikat Tradisional Kupang Ntt. Soulmath, 4(5), 251-256. https://doi.org/10.25139/sm.v4i5.232 